\title{
Pseudoallencotyla gen. n., a new genus for Allencotyla pricei (Kritsky, Noble et Moser, 1978) (Monogenea: Heteraxinidae), with a key to genera of Heteraxininae
}

\author{
Francisco E. Montero, F. Javier Aznar, Mercedes Fernández and Juan A. Raga \\ Departamento de Zoología and Instituto Cavanilles de Biodiversidad y Biología Evolutiva, Universitat de València, \\ P.O. Box 22085, Valencia 46071, Spain
}

Key words: Monogenea, Polyopisthocotylea, Heteraxininae, Allencotyla pricei, Pseudoallencotyla

\begin{abstract}
In this study, we clarify the taxonomic status of Allencotyla pricei based on a re-examination of paratypes and voucher specimens. Four important characters are added to previous descriptions: the vagina is ventral; the cirrus is absent; the eggs are fusiform and have two polar filaments (one about 3.5 times longer than the other); and, there are two flat sclerites at each side of the dorsal trident-shaped sclerite in the clamps. A comparison of $A$. pricei with species from all the genera of the Heteraxininae, including Allencotyla mcintoshi, indicates that $A$. pricei has several exclusive characters, i.e., a ventral vagina, vaginal armature, two additional dorsal sclerites in the clamps, a ventral mouth, and a question mark-shaped ovary. The combination of characters found in A. pricei is not shared with any other species within the Heteraxininae. In view of these features, $A$. pricei is assigned to a new genus, Pseudoallencotyla gen. n., as P. pricei comb. n.
\end{abstract}

Allencotyla Price, 1962 currently contains two species, A. mcintoshi Price, 1962 and A. pricei Kritsky, Noble et Moser, 1978. The type-species, A. mcintoshi, was recently redescribed based on re-examination of the type-specimens and the study of new material collected from greater amberjacks, Seriola dumerili (Risso, 1810) (Carangidae) in the Spanish Mediterranean (Montero et al. 2003). Contrary to the original description of this monogenean, the cirrus was observed to be armed and the vagina was covered with pointed folds, not with spines. Both characters have been used to distinguish genera within the Heteraxininae (see Unnithan 1957, Price 1962, Yamaguti 1963, Mamaev 1970, Kritsky et al. 1978, Bravo-Hollis 1984) and, therefore, the diagnosis of Allencotyla was emended (Montero et al. 2003). A question that arises is whether the generic position of $A$. pricei is affected by the emended generic diagnosis.

In this paper, we re-examine the generic status of $A$. pricei based on the study of available material, including paratypes and voucher specimens collected from several surfperch species (Embiotocidae) in Southern California (Kritsky et al. 1978, Payne 1990). We add important new characters to the descriptions of A. pricei by Kritsky et al. (1978) and Payne (1990), and compare the morphology of $A$. pricei and A. mcintoshi, paying particular attention to divergences in characters likely to have significance at the generic level (see references above). Finally, we discuss the taxonomic position of $A$. pricei based on a comparison of characters among other genera of the Heteraxininae.

\section{MATERIALS AND METHODS}

Paratypes $(\mathrm{n}=3)$ and voucher specimens $(\mathrm{n}=7)$ of $A$. pricei from four host species in the Embiotocidae were reexamined using light microscopy (Table 1). Specific structures were drawn with the aid of a drawing tube. Specimens of $A$. price $i$ were compared with 44 specimens of $A$. mcintosh $i$ from two host species in the Carangidae, which had previously been described by Montero et al. (2003) (Table 1). The generic assignment of $A$. pricei was investigated based on a comparison of relevant generic-level characters in the taxonomy of the Heteraxininae that were selected according to Tripathi (1957), Unnithan (1957, 1971), Price (1962), Yamaguti (1963), Mamaev (1970, 1990), Ogawa and Egusa (1977), Kritsky et al. (1978), Bravo-Hollis (1984) and Payne (1990).

\section{RESULTS AND DISCUSSION}

\section{New morphological features of $\boldsymbol{A}$. pricei}

The description of $A$. pricei is accurate and rather detailed (Kritsky et al. 1978). The main morphological features are illustrated in Fig. 1. A re-examination of available material revealed four new important characters. First, the vagina is ventral and not dorsal as Kritsky et al. (1978) indicated. Second, the specimens examined do not have a cirrus; in the original description, Kritsky et al. (1978) did not mention anything about this structure. Third, the egg of $A$. price $i$ was not described, but in voucher specimens Nos. 80952 (USNPC) and 31150 (HWML) (see Table 1), two eggs were found, measuring $254 \times 59$ and $340 \times 101 \mu \mathrm{m}$. Eggs had two

Address for correspondence: F.E. Montero, Departamento de Zoología and Instituto Cavanilles de Biodiversidad y Biología Evolutiva, Universitat de València, P.O. Box 22085, Valencia 46071, Spain. Phone: ++34 963543657 ; Fax: ++34 963543670 ; E-mail: Francisco.E.Montero@uv.es 
polar filaments, one notably longer (1,820 and 2,330 $\mu \mathrm{m})$ than the other $(528$ and $624 \mu \mathrm{m})($ Fig. 1B, C) [eggs were somewhat distorted, so morphometrical measurements should be considered with caution]. Fourth, two flat sclerites were observed at each side of the dorsal trident-shaped sclerite in the clamps (Fig. 1D). These sclerites were not mentioned in previous descriptions, although they were featured in the illustration provided by Kritsky et al. (1978).

\section{Comparison between $A$. pricei and $A$. mcintoshi}

There are fundamental morphological differences between $A$. pricei and A. mcintoshi (see Price 1962 and Montero et al. 2003, for a morphological description of A. mcintoshi). (1) The cirrus is absent in A. pricei but present in $A$. mcintoshi. (2) The vaginal pore of $A$. pricei (Fig. 1E) is ventral and surrounded by armature with a defined architecture, comprising two tiers of two different types of long and well-developed spines, and a third tier containing two lateral muscular plaques (see Kritsky et al. 1978). In contrast, the vaginal pore of $A$. $m c i n t o s h i$ is dorsal and surrounded by pointed folds, not spines (Montero et al. 2003). (3) The following differences exist in the morphology of the armature of the genital atrium (Fig. 1F). Individuals of $A$. price $i$ have 3 crowns of 49-56 spines; the spines of the inner crown have a different size and shape compared with those of the two outer crowns. However, individuals of A. mcintoshi have 8 crowns of numerous spines (321456) of similar size and shape. (4) The mouth cavity of $A$. pricei is a ventral transverse narrow opening (Fig. $1 \mathrm{G})$, whereas that of $A$. mcintoshi opens as a subapical wide aperture. (5) The anterior end of $A$. mcintoshi has two open, elliptical and strongly septate suckers preceded by a glandular thickening of the tegument (referred to as sticky convoluted tegument in Zeuxapta seriolae by Rohde 1981), whereas that of $A$. pricei lacks the glandular thickening of the tegument and has slightly septate suckers of more closed and subcircular appearance (Fig. 1G). (6) The clamps of $A$. pricei bear two sclerites (Fig. 1D) that are absent in A. mcintoshi; in addition, clamp size between both sides of the haptor is similar in A. pricei, but dissimilar in A. mcintoshi (see Kritsky et al. 1978). (7) The ovary of $A$. mcintoshi is long and begins with a globular region followed by a narrow, long inverted U-shaped region; however, $A$. pricei has a shorter ovary without a globular region, and a "question mark" shape (Kritsky et al. 1978) (Fig. 1H). (8) The eggs of $A$. pricei have two filaments (Fig. 1B, C), whereas those of $A$. mcintosh $i$ have only one.

The differences between $A$. mcintoshi and $A$. pricei have sound taxonomic significance. In particular, the presence/absence of a cirrus, the location of the vaginal pore (dorsal vs. ventral) and the presence/absence of vaginal armature are characters typically used to separate genera in the Heteraxininae (see Price 1962). In addition, clamp morphology and size differ between $A$. pricei and A. mcintoshi, characters which have previously been used to separate taxa within the Microcotyloidea Unnithan, 1957 (Unnithan 1957, Price 1962, Yamaguti 1963, Mamaev 1970, Bravo-Hollis 1984). Finally, there are differences in other important characters, e.g. the number of polar filaments on the egg. We therefore conclude that $A$. pricei is sufficiently different from $A$. mcintoshi to be placed in a separate genus.

\section{Taxonomic position of $\boldsymbol{A}$. pricei}

Allencotyla pricei has the diagnostic features of the Heteraxininae (see Kritsky et al. 1978). In Table 2, characters to distinguish genera are compared between $A$. pricei and other genera of the Heteraxininae. Based on the available morphological evidence, two conclusions can be drawn. First, A. pricei has several exclusive characters, namely, a ventral vagina, vaginal armature, two additional dorsal sclerites in the clamps, a ventral mouth, and a question mark-shaped ovary. Second, the combination of other characters is not shared with other species of the Heteraxininae (Table 2). We therefore propose a new genus to include $A$. pricei.

\section{Pseudoallencotyla gen. n.}

Diagnosis: Heteraxinidae, Heteraxininae. Anterior end with two subcircular suckers, each divided by slightly marked septa. Robust haptoral clamps with two additional dorsal flat sclerites. Oral cavity ventral. Pharynx small; intestinal bifurcation posterior to vagina; crura ramified, extending into haptor. Testes numerous, post-ovarian, intercaecal. Genital atrium armed, ventral; cirrus absent. Ovary question mark-shaped, intercaecal. Vagina armed, mid-ventral. Egg with two polar filaments. Type species: Pseudoallencotyla pricei (Kritsky, Noble et Moser, 1978) comb. n. Description in Kritsky et al. (1978); additional data in Payne (1990).

$\mathrm{E} \mathrm{y} \mathrm{m}$ o $1 \mathrm{o} \mathrm{g} \mathrm{y}$ : The name derives from the previous assignment of this species.

It is worthwhile noting that most of the diagnostic characters of Pseudoallencotyla are common to Leuresthicola Price, 1962, which belongs to a different subfamily, the Monaxininae Unnithan, 1957. The two subfamilies, Monaxininae and Heteraxininae, belong to the Heteraxinidae, and only differ in the presence of clamps on one or two sides of the haptor. We examined two specimens of Leuresthicola sp. (USNPC Acc. No. 49353) from Leuresthes tenuis (Atherinidae) and confirmed that this species also has vaginal spines (not previously described, see Price 1962), an armed genital atrium, a ventral mouth, eggs with two filaments, dorsal flat sclerites in the clamps, and a question mark-shaped ovary; it also lacks a cirrus. The striking resemblance between both genera suggests that a thorough revision of the diagnostic characters within the Heteraxinidae 


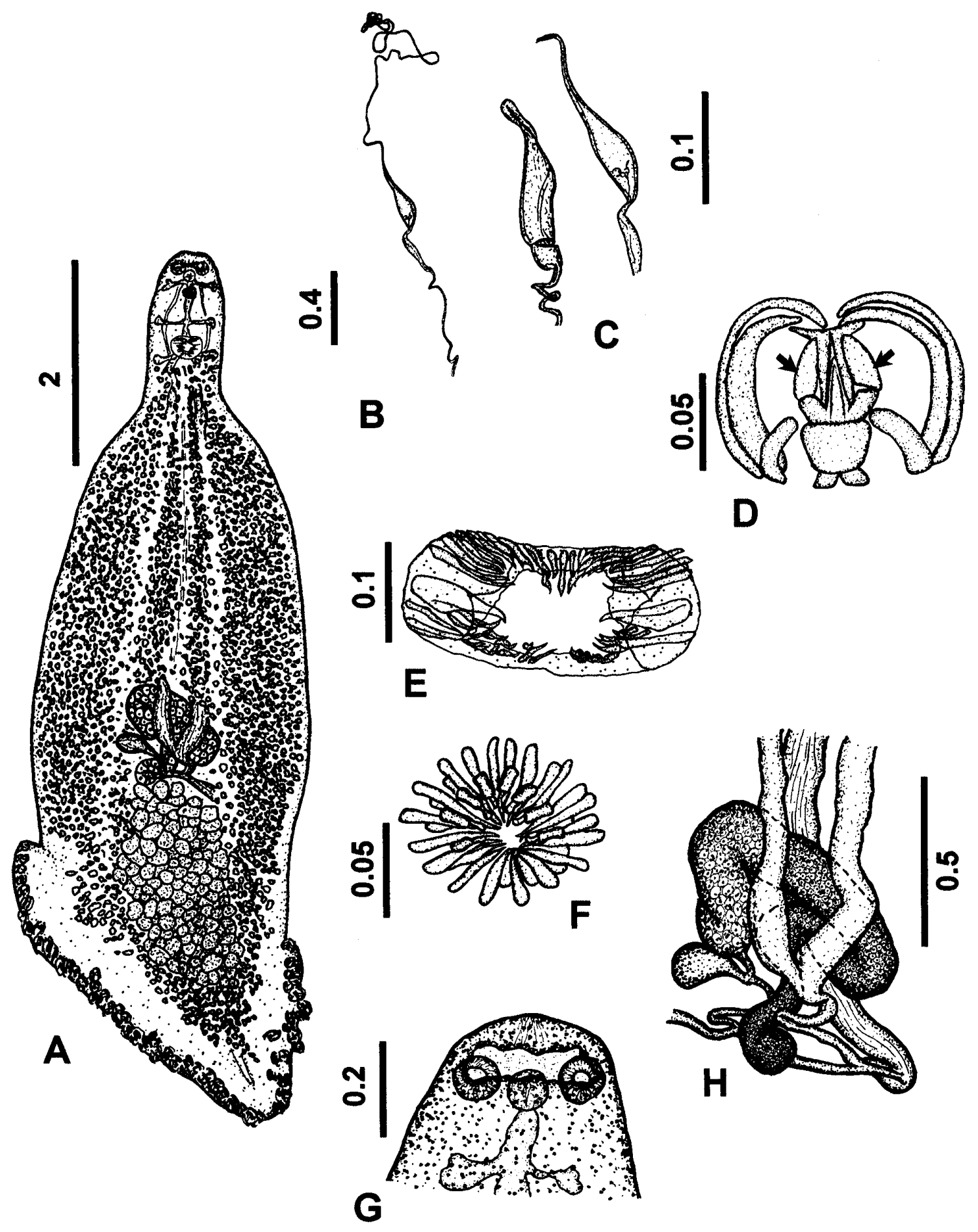

Fig. 1. Pseudoallencotyla pricei (Kritsky, Noble et Moser, 1978). A - specimen in toto; B, C - eggs; D - clamp (dorsal view), the arrows indicate the dorsal flat sclerites; $\mathbf{E}$ - vaginal pore (ventral view); $\mathbf{F}$ - genital atrium (ventral view); $\mathbf{G}$ - anterior body end (ventral view); $\mathbf{H}$ - ovary (ventral view). Scale bars in $\mathrm{mm}$. 
Table 1. Specimens of Allencotyla examined in this study ( $\mathrm{n}$ - number of specimens examined; Acc. Nos. - registration and accession numbers; USNPC - United States National Parasite Collection; ICBIBE - parasitological collection of the Institute of Biodiversity and Evolutionary Biology, University of Valencia; HWML - Harold W. Manter Laboratory of Parasitology, University of Nebraska State Museum, Lincoln, Nebraska).

\begin{tabular}{|c|c|c|c|c|l|c|}
\hline Parasite species & $\mathrm{n}$ & Specimens status & Source & Acc. Nos. & \multicolumn{1}{|c|}{ Host species } & Locality \\
\hline \multirow{4}{*}{ Allencotyla mcintoshi $i$} & 1 & holotype & USNPC & 37730 & Seriola lalandi & Florida, USA \\
& 4 & paratypes & USNPC & 37731 & Seriola lalandi & Florida, USA \\
& 35 & vouchers & USNPC & $90915 / 16 / 17$ & Seriola dumerili & Murcia, Spain \\
& 2 & varatypes & USNPC & 74633 & Rhacochilus vacca & California, USA \\
& 1 & voucher & USNPC & 76473 & Embiotoca lateralis & California, USA \\
& 1 & voucher & USNPC & 80952 & Rhacochilus vacca & California, USA \\
Allencotyla pricei $i$ & 1 & voucher & USNPC & 80953 & Embiotoca jacksoni & California, USA \\
& 1 & paratype & HWML & 20861 & Rhacochilus vacca & California, USA \\
& 2 & vouchers & HWML & 31150 & Rhacochilus vacca & California, USA \\
& 1 & voucher & HWML & 31151 & Embiotoca jacksoni & California, USA \\
& 1 & voucher & HWML & 31152 & Phanerodon atripes & California, USA \\
\hline
\end{tabular}

Table 2. Diagnostic characters of the Heteraxininae (see references in the text). Asterisks indicate characters traditionally used at subfamilial level. (+) presence, (-) absence, (?) unknown, (D) dorsal, (V) ventral, (2L) double and lateral, (S) subapical.

\begin{tabular}{|c|c|c|c|c|c|c|c|c|c|}
\hline & $\begin{array}{l}\text { Allen- } \\
\text { cotyla }\end{array}$ & $\begin{array}{c}\text { Heter- } \\
\text { axine }\end{array}$ & $\begin{array}{c}\text { Heter- } \\
\text { axinoides }\end{array}$ & $\begin{array}{c}\text { Karavoli- } \\
\text { cotyla }\end{array}$ & $\begin{array}{l}\text { Lethrin- } \\
\text { axine }\end{array}$ & Probursata & Tripathiana & Zeuxapta & A. pricet \\
\hline Vagina* & $+/ \mathrm{D}$ & $+/ \mathrm{D}$ & - & +/D & $+/ \mathrm{D}$ & $+/ 2 \mathrm{~L}$ & $+/ \mathrm{D}$ & $+/ \mathrm{D}$ & $+/ \mathrm{V}$ \\
\hline Vaginal armature* & - & - & - & - & - & - & - & - & + \\
\hline Accessory vagina* & - & + & - & - & - & - & - & - & - \\
\hline $\begin{array}{l}\text { Genital atrium } \\
\text { armature* }\end{array}$ & + & - & + & + & - & - & + & - & + \\
\hline Cirrus* & + & + & + & + & + & - & + & + & - \\
\hline Cirrus armature* & $+/-$ & - & $+/-$ & - & + & - & + & - & - \\
\hline Flat clamp sclerites & - & - & - & - & - & - & - & - & + \\
\hline Mouth & $\mathrm{S}$ & $\mathrm{S}$ & $\mathrm{S}$ & $\mathrm{S}$ & $\mathrm{S}$ & $\mathrm{S}$ & $\mathrm{S}$ & $\mathrm{S}$ & V \\
\hline U-shaped ovary & + & + & + & + & + & + & + & + & - \\
\hline $\begin{array}{l}\text { Number of egg } \\
\text { filaments }\end{array}$ & 1 & 1 & 1 & 2 & $?$ & $?$ & $?$ & 1 & 2 \\
\hline
\end{tabular}

may be necessary. Phylogenetic analyses could help to clarify the systematics of this family.

Based on data in the present study and the recently emended diagnosis of the genus Allencotyla (Montero et al. 2003), we suggest the following key to the genera of the Heteraxininae:

1 Vagina absent Heteraxinoides Yamaguti, 1963

- Vagina present .. 2

2 Vaginal pore(s) ventral and armed Pseudoallencotyla gen. $\mathrm{n}$.

- Vaginal pore(s) not located ventrally and unarmed .. 3

3 Two vaginal pores; genital atrium armed

Probursata Bravo-Hollis, 1984

- One vaginal pore; genital atrium armed or unarmed ...

Genital atrium unarmed ........................................... 4

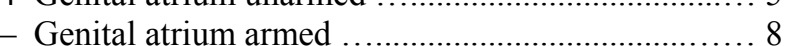

5 Accessory vaginal pore present .

- Accessory vaginal pore absent

Heteraxine Yamaguti, 1963

7 Cirrus armed

Lethrinaxine Mamaev, 1977 Cirrus unarmed Zeuxapta Unnithan, 1957

8 Clamps of long side of haptor forming two groups of distinct size; largest clamps in the anterior end

Tripathiana Unnithan, 1971

- Clamps of long side of haptor gradually larger towards the centre

9 Egg monofilamented .......... Allencotyla Price, 1962

- Egg bifilamented Karavolicotyla Price, 1962

Acknowledgements. We thank the US National Museum and the Harold W. Manter Laboratory for the loan of specimens. Thanks are also due to Dr. D. Kritsky for his kind comments and assistance. This study was supported by projects OCYT No. GV-01-9 from the Valencian Government and BOS2002878 from the Spanish Government. F.J. Aznar benefits from a postdoctoral contract from the MCYT of Spain. 


\section{REFERENCES}

BRAVO-HOLLIS M. 1984: Monogenea (Van Beneden, 1858) Carus, 1863 de peces marinos del Golfo de México y del Mar Caribe. IX. Descripción de un género y una especie nuevos de la familia Heteraxinidae, Price 1962, subfamilia Heteraxininae Unnithan, 1957. An. Inst. Biol. Univ. Nac. Autón. Méx. 54: 1-11.

KRITSKY D.C., NOBLE E.R., MOSER M. 1978: Allencotyla pricei sp. n. (Microcotyloidea: Heteraxinidae) from the gills of the pile surfperch, Damalichthys vacca (Girard), in Southern California. J. Parasitol. 64: 45-48.

MAMAEV YU.L. 1970: [Helminths of some food fishes of the Gulf of Tonkin. In: Helminths of Animals of Southeast Asia.] Izd. "Nauka", Moskva. Siberian Dep. Far Eastern Branch Acad. Sci. USSR, p. 127-190. (In Russian.)

MAMAEV YU.L. 1990: The systematical composition of the family Heteraxinidae and other allied families of Monogenea. Folia Parasitol. 37: 225-230.

MONTERO F.E., AZNAR F.J., FERNÁNDEZ M., RAGA J.A. 2003: Redescription of Allencotyla mcintoshi Price, 1962 (Monogenea), with an emended diagnosis of Allencotyla Price, 1962. J. Parasitol. 89 (in press).

OGAWA K., EGUSA E. 1977: Redescription of Heteraxine heterocerca (Monogenea: Heteraxinidae). Jpn. J. Parasitol. 26: $388-396$.

Received 11 February 2002
PAYNE R.R. 1990: Four new Monogenea (Axinidae and Heteraxinidae) from Eastern Pacific Ocean fishes. J. Helminthol. Soc. Wash. 37: 93-103.

PRICE E.W. 1962: North American monogenetic trematodes. XI. The family Heteraxinidae. J. Parasitol. 48: 402-418.

ROHDE K. 1981: Ultrastructure of the buccal organs and associated structures of Zeuxapta seriolae (Meserve, 1938) Price, 1962 and Paramicrocotyloides reticularis Rohde, 1978 (Monogenea, Polyopisthocotylea). Zool. Anz. 206: 279-291.

TRIPATHI Y.R. 1957: Monogenetic trematodes from fishes of India. Indian J. Helminthol. 9: 1-149.

UNNITHAN V.N. 1957: On the functional morphology of a new fauna of Monogenea of fishes of Trivandrum and environs. Part I. Axinidae fam. nov. Bull. Cent. Res. Inst. Univ. Kerala India 5: 27-122.

UNNITHAN V.N. 1971: Patterns of secondary growth and a revision of the systematics in Microcotyloidea and Gastrocotylidae (Monogenoidea). Rec. Zool. Surv. India, 65: $17-88$.

YAMAGUTI S. 1963: Systema Helminthum. IV. Monogenea and Aspidocotylea. Interscience Publishers, John Wiley and Sons, New York, 699 pp.

Accepted 31 July 2002 